\title{
Polysiloxane Bonded Silica Aerogel with Enhanced Thermal Insulation and Strength
}

\author{
Weilin Wang, Zongwei Tong ${ }^{(0)}$, Ran Li, Dong Su * and Huiming Ji * \\ Key Laboratory for Advanced Ceramics and Machining Technology of Ministry of Education, \\ School of Materials Science and Engineering, Tianjin University, Tianjin 300072, China; \\ wangweilin@tju.edu.cn (W.W.); tongzongwei@tju.edu.cn (Z.T.); lir184@tju.edu.cn (R.L.) \\ * Correspondence: sudong@tju.edu.cn (D.S.); jihuiming@tju.edu.cn (H.J.)
}

Citation: Wang, W.; Tong, Z.; Li, R.; $\mathrm{Su}, \mathrm{D}$.; Ji, H. Polysiloxane Bonded Silica Aerogel with Enhanced Thermal Insulation and Strength. Materials 2021, 14, 2046.

https://doi.org/10.3390/ma14082046

Academic Editor: Csaba Balázsi

Received: 23 March 2021

Accepted: 17 April 2021

Published: 19 April 2021

Publisher's Note: MDPI stays neutral with regard to jurisdictional claims in published maps and institutional affiliations.

Copyright: (c) 2021 by the authors. Licensee MDPI, Basel, Switzerland. This article is an open access article distributed under the terms and conditions of the Creative Commons Attribution (CC BY) license (https:// creativecommons.org/licenses/by/ $4.0 /)$.

\begin{abstract}
In order to improve the mechanical properties of $\mathrm{SiO}_{2}$ aerogels, $\mathrm{PHMS} / \mathrm{VTES}-\mathrm{SiO}_{2}$ composite aerogels $\left(\mathrm{P} / \mathrm{V}-\mathrm{SiO}_{2}\right)$ were prepared. Using vinyltriethoxysilane (VTES) as a coupling agent, the PHMS/VTES complex was prepared by conducting an addition reaction with polyhydromethylsiloxane (PHMS) and VTES and then reacting it with inorganic silica sol to prepare the organic-inorganic composite aerogels. The PHMS/VTES complex forms a coating structure on the aerogel particles, enhancing the network structure of the composite aerogels. The composite aerogels can maintain the high specific surface area and excellent thermal insulation properties, and they have better mechanical properties. We studied the reaction mechanism during preparation and discussed the effects of the organic components on the structure and properties of the composite aerogels. The composite aerogels we prepared have a thermal conductivity of $0.03773 \mathrm{~W} \cdot \mathrm{m}^{-1} \cdot \mathrm{K}^{-1}$ at room temperature and a compressive strength of $1.87 \mathrm{MPa}$. The compressive strength is several times greater than that of inorganic $\mathrm{SiO}_{2}$ aerogels. The organic-inorganic composite aerogels have excellent comprehensive properties, which helps to expand the application fields of silicon-based aerogels.
\end{abstract}

Keywords: silicon-based aerogel; polysiloxane; organic-inorganic composite; coating; thermal insulation properties; mechanical properties

\section{Introduction}

$\mathrm{SiO}_{2}$ aerogels have many advantages, including low thermal conductivity, low density and large specific surface area [1-3]. They can be used for thermal insulation [4,5], oil-water separation [6], wastewater treatment [7], sound insulation [8] and catalysts [9]. However, the mechanical properties of $\mathrm{SiO}_{2}$ aerogels are poor. The compressive strength of the $\mathrm{SiO}_{2}$ aerogels prepared by ambient pressure drying is generally less than $0.6 \mathrm{MPa}[10,11]$. This is because $\mathrm{SiO}_{2}$ aerogels have a three-dimensional network structure composed of nanoparticles. The network can easily collapse under the action of external forces, resulting in the poor mechanical properties of $\mathrm{SiO}_{2}$ aerogels [12]. In order to enhance the mechanical properties of $\mathrm{SiO}_{2}$ aerogels, the following methods have been proposed: changing precursor [13,14], organic polymer reinforcement [7,15] and fiber reinforcement [16,17]. We focused on two methods: changing precursor and organic polymer reinforcement.

On the one hand, some precursors are used to replace tetraethyl orthosilicate (TEOS) to prepare the silicon-based aerogels. Common precursors are low-molecular-weight silanes, including methyltrimethoxysilane (MTMS) [18] and vinyltriethoxysilane (VTES) [19]. These precursors all have a non-hydrolyzable group (such as methyl and vinyl), which can enhance the elasticity of aerogels and reduce the fragility of aerogels [20]. However, this method decreases the specific surface area of the silicon-based aerogels [21]. Gen et al. used vinyltrimethoxysilane (VTMS) and vinylmethyldimethoxysilane (VMDMS) as precursors to prepare elastic aerogels [22]. Ma et al. used VTES/TEOS and MTES/TEOS as precursors to prepare the silicon-based aerogels. It was found that the aerogels prepared by using VTES/TEOS had better mechanical properties, and the compressive strength could reach 
1.45-3.17 MPa; however, the specific surface area was only $365-488 \mathrm{~m}^{2} / \mathrm{g}$ [23]. However, in these studies, they only focused on improving the mechanical properties by changing precursors. The thermal insulation properties of the composite aerogels were not studied.

On the other hand, through the condensation reaction of silica sol and organic polymers, the last are connected with the aerogel network to form polymer-enhanced composite aerogels. Liu et al. used polyurethane to reinforce $\mathrm{SiO}_{2}$ aerogels, which increased the compressive strength of the composite aerogels to $4 \mathrm{MPa}$. However, the specific surface area significantly decreased to only $346 \mathrm{~m}^{2} / \mathrm{g}$ [24]. With $\mathrm{NaOH}$ as a catalyst, Lin et al. prepared the composite aerogels using polyhydromethylsiloxane (PHMS) and TEOS. The specific surface area of the composite aerogels was still small, ranging from 284 to $576 \mathrm{~m}^{2} / \mathrm{g}$ [25].

In our study, in order to comprehensively improve the thermal insulation properties and mechanical properties of the silicon-based aerogels, we used the two methods, changing precursor and organic polymer reinforcement, at the same time. The new precursor (VTES) and polymer (PHMS) were used to prepare the PHMS/VTES complex through an addition reaction. Next, the PHMS/VTES-SiO 2 composite aerogels $\left(\mathrm{P} / \mathrm{V}-\mathrm{SiO}_{2}\right)$ were prepared by a condensation reaction of the PHMS/VTES complex and inorganic silica sol. The PHMS/VTES complex formed a coating structure on the aerogel particles, achieving chemical bonding between adjacent aerogel particles, which improved the strength of the aerogel network. Therefore, the mechanical properties of the composite aerogels could be improved, while maintaining the high specific surface area and the thermal insulation properties. We analyzed the structure of the composite aerogels and discussed the effects of PHMS and VTES on the structure and properties of the composite aerogels. It provided a new idea for preparing the silicon-based aerogels with high specific surface area, low thermal conductivity and high strength.

\section{Materials and Methods}

\subsection{Materials}

The following materials were sourced as indicated. Polyhydromethylsiloxane (PHMS, $1.55 \%$, calculated by hydrogen) was from Kaihuasantai, Quzhou, China. Platinum divinyltetramethyldisiloxane complex (2\%, calculated by platinum) was from Anpin Silicone Materials, Shenzhen, China. Isopropanol (99\%) and formamide (99\%) were from Fuchen, Tianjin, China. Triethoxyvinylsilane (VTES, 97\%), tetraethyl orthosilicate (TEOS, 98\%), trimethylsilylchloride (TMCS, 98\%), methyltrimethoxysilane (MTMS, 98\%), methyltriethoxysilane (MTES, 98\%), nitric acid (63\%), propylene oxide (99\%) and n-hexane $(97 \%)$ were all from Aladdin, Shanghai, China. All the materials were of analytical grade and used directly, without further treatment of purification.

\subsection{Experimental Procedure}

The preparation of the PHMS/VTES-SiO ${ }_{2}$ composite aerogels $\left(\mathrm{P} / \mathrm{V}-\mathrm{SiO}_{2}\right)$ was divided into three stages: (1) preparation of the PHMS/VTES complex, (2) preparation of the wet gels and (3) post-processing of the composite aerogels. All reactions were carried out in beakers.

\subsubsection{Preparation of the PHMS/VTES Complex}

PHMS and VTES underwent an addition reaction at $45^{\circ} \mathrm{C}$ with platinum divinyltetramethyldisiloxane complex as the catalyst. The amount of the catalyst was $1 \mathrm{wt} . \%$ of PHMS and VTES. The PHMS/VTES complex was obtained in $10 \mathrm{~min}$.

\subsubsection{Preparation of the Wet Gels}

Firstly, TEOS, isopropanol and deionized water were mixed at the volume ratio of 1.0:1.6:0.5. Nitric acid was added to adjust the $\mathrm{pH}$ to 2 . The mixture was reacted for $5 \mathrm{~h}$. Then, propylene oxide was added to adjust the $\mathrm{pH}$ to 5 to 6 , and formamide was added to optimize the network structure of gels. Calculated by volume, the amount of formamide was 0.16 times of TEOS. Next, the inorganic silica sol and organic components were mixed, 
and then poured into molds. The formulation is shown in Table 1. The wet gels were generated in approximately $12 \mathrm{~h}$, at $40{ }^{\circ} \mathrm{C}$.

Table 1. Formulation of the organic-inorganic composite aerogels (mole ratio).

\begin{tabular}{cccc}
\hline Samples & PHMS * & VTES & TEOS \\
\hline $\mathrm{P} / \mathrm{V}-\mathrm{SiO}_{2}-1$ & 1.0 & 0.3 & 3.5 \\
$\mathrm{P} / \mathrm{V}-\mathrm{SiO}_{2}-2$ & 1.0 & 0.3 & 5.0 \\
$\mathrm{P} / \mathrm{V}-\mathrm{SiO}_{2}-3$ & 1.0 & 0.3 & 6.5 \\
$\mathrm{P} / \mathrm{V}-\mathrm{SiO}_{2}-4$ & 1.0 & 0.3 & 8.0 \\
\hline
\end{tabular}

* The amount of PHMS is calculated based on the hydrogen content of PHMS.

\subsubsection{Post-Processing of the Composite Aerogels}

The post-process of the composite aerogels included aging, alcohol-water exchange, surface modification and ambient pressure drying. First, the wet gels were soaked in isopropanol and aged at $45-60{ }^{\circ} \mathrm{C}$ for $48 \mathrm{~h}$. Next, an alcohol-water exchange was performed at room temperature, and the water in the wet gels was replaced with ethanol and isopropanol. The replacement was performed every $8 \mathrm{~h}$, for a total of 6 times. Third, surface modification was performed to replace the hydrophilic groups on the surface of the wet gels with hydrophobic groups to reduce the collapse of pores due to water evaporation during the drying process. The modification process was performed under two conditions, using n-hexane as the solvent: The first time, trimethylchlorosilane was used; the second time, methyltrimethoxysilane and methyltriethoxysilane were used to obtain a better modification effect [11]. The volume ratio of solvent to modifiers was 9:1. The time for each modification was $24 \mathrm{~h}$, and the temperature was $50^{\circ} \mathrm{C}$. Finally, drying at $80^{\circ} \mathrm{C}$ for $3-5 \mathrm{~h}$ was conducted to obtain the organic-inorganic composite aerogels.

\subsection{Characterizations}

In this study, the morphology of the composite aerogels was studied by scanning electron microscopy (SEM; Hitachi, S-4800, Tokyo, Japan) at an acceleration voltage of $3 \mathrm{kV}$. Before SEM analysis, the samples underwent the treatment of gold sputtering to enhance conductivity. The chemical composition of the composite aerogels was characterized by Fourier-transform infrared spectroscopy (FTIR; Thermo, Nicolet iS5, Waltham, MA, USA). The pore structure was analyzed by a Surface Area and Pore Size Analyzer (Quantachrome, NOVA 2200e, Boynton Beach, FL, USA) with $\mathrm{N}_{2}$ as an adsorbent. The specific surface area was calculated using Brunauer-Emmett-Teller (BET) method, and the pore size distribution was calculated by using the Barrett-Joyner-Halenda $(\mathrm{BJH})$ method. Before the analysis of pore structure, the samples underwent the treatment of degassing at $130^{\circ} \mathrm{C}$, for $15 \mathrm{~h}$. Thermal conductivity was measured by the hot-wire method, using a thermal conductivity measuring instrument (XIATECH, TC3000, $\mathrm{Xi}^{\prime}$ an, China). During the measurement, the heating voltage was $0.9 \mathrm{~V}$, and the sampling time was $2 \mathrm{~s}$. Compressive strength was measured by a digital mechanical strength measurement instrument (KEBAO, DL-15, Dongguan, China) with a load application speed of $0.1 \mathrm{~mm} / \mathrm{min}$.

\section{Results}

\subsection{Microscopic Morphology and Structural Characteristics of the Composite Aerogels}

The preparation of the composite aerogels can be divided into three stages: (1) The organic polymer (PHMS) and coupling agent (VTES) formed the PHMS/VTES complex by an addition reaction. (2) The PHMS/VTES complex reacted with silica sol to form composite gels. (3) The composite aerogels were obtained from the composite gels by ambient pressure drying. The process and mechanism are shown in Figure 1. 


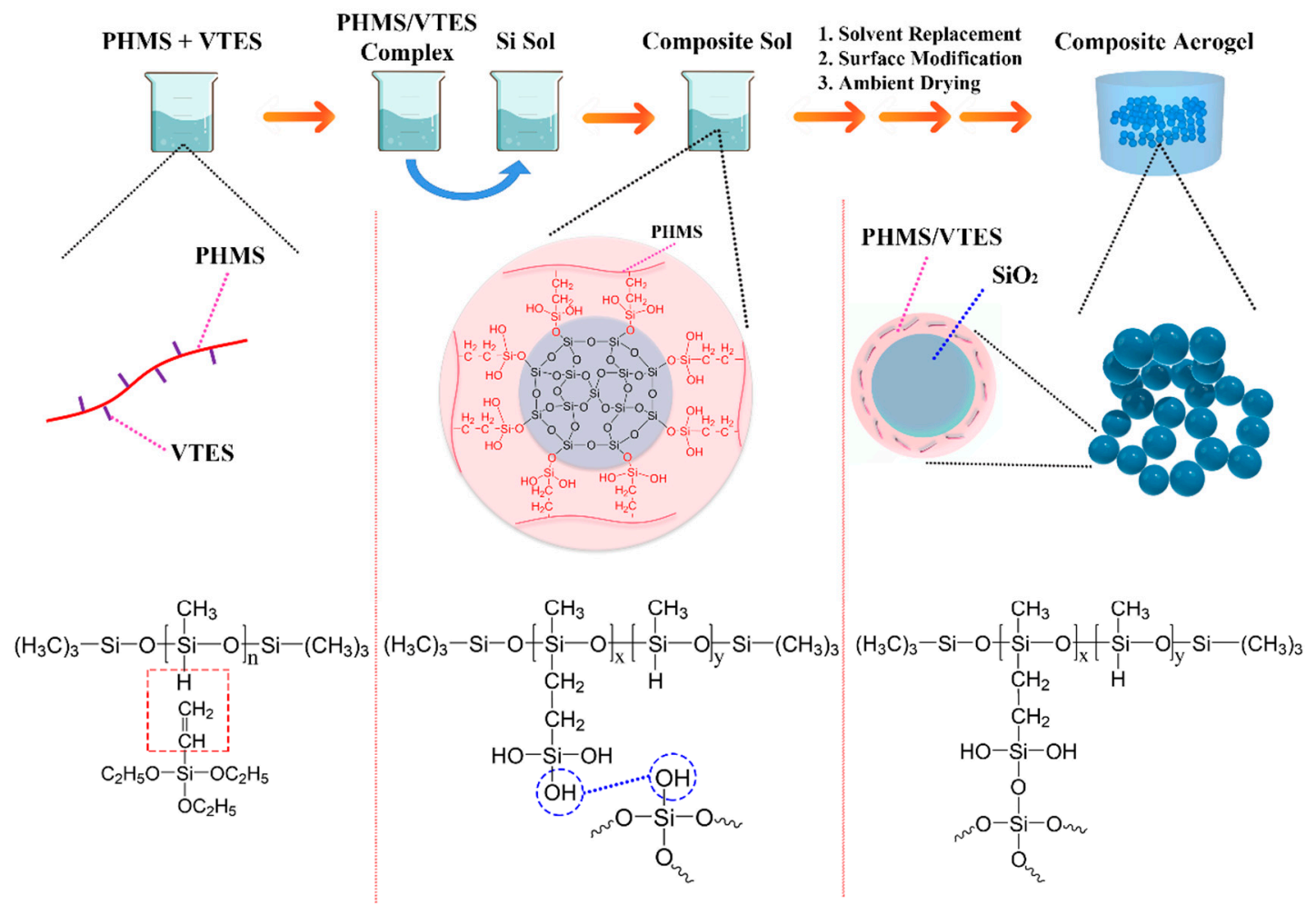

Figure 1. Preparation process and preparation mechanism of the composite aerogels.

\subsubsection{Chemical Composition and Reaction Mechanism}

During the addition reaction between PHMS and VTES, the samples in the reaction were analyzed by infrared spectroscopy, as shown in Figure 2A. The peak at $2980 \mathrm{~cm}^{-1}$ was attributable to the stretching vibration of methyl group. The peaks at 2926 and $2884 \mathrm{~cm}^{-1}$ were attributable to the stretching vibration of methylene group [26]. There were two sources of methylene: the ethoxy $\left(-\mathrm{OCH}_{2} \mathrm{CH}_{3}\right)$ of VTES and $\mathrm{Si}-\mathrm{CH}_{2}-\mathrm{CH}_{2}-\mathrm{Si}$ generated in the addition reaction between PHMS and VTES. By quantitative analysis of the methylene content, the progress of the addition reaction could be estimated. In quantitative analysis, the stronger absorption peak at $2926 \mathrm{~cm}^{-1}$ represented methylene (Figure 2B). The peak intensity was normalized according to the absorption peak of the methyl group at $2980 \mathrm{~cm}^{-1}$. As shown in Figure 2C, as the reaction progressed, the stretching vibration peak of methylene increased. This was due to the formation of $\mathrm{Si}-\mathrm{CH}_{2}-\mathrm{CH}_{2}-\mathrm{Si}$ by the addition reaction between $\mathrm{Si}-\mathrm{H}$ bond and $\mathrm{C}=\mathrm{C}$ bond, which indicated that the addition reaction proceeded gradually. The absorption peak of $C=C$ bond at $1620 \mathrm{~cm}^{-1}$ and the absorption peak of Si-H bond at $2200 \mathrm{~cm}^{-1}$ decreased as the reaction progressed, which also proved that the addition reaction was proceeded gradually. After $10 \mathrm{~min}$, the absorption peak of $C=C$ at $1620 \mathrm{~cm}^{-1}$ tended to disappear, indicating that PHMS and VTES had sufficiently reacted. 
(A)

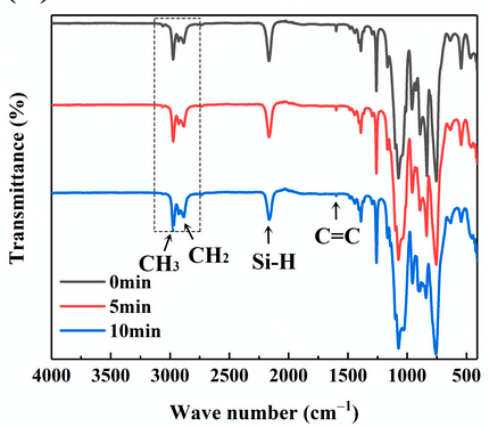

(B)

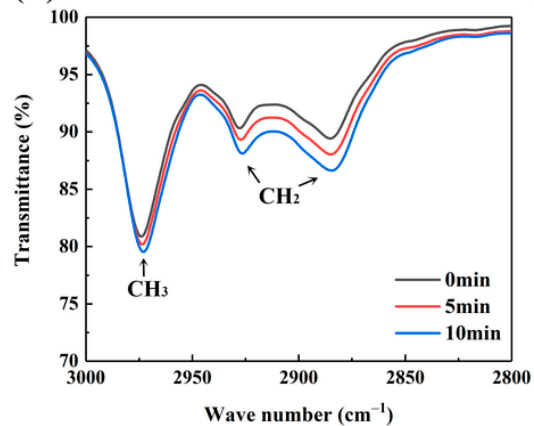

(C)

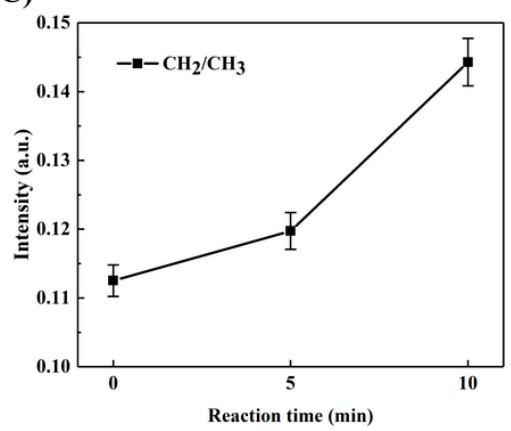

Figure 2. Infrared spectra of the addition reaction of PHMS and VTES: (A) complete infrared spectrum; (B) enlarged view of part of the spectra shown in (A), in the wavenumber range of $2800-3000 \mathrm{~cm}^{-1}$; (C) quantitative analysis of methylene.

The infrared spectrum of the composite aerogels is shown in Figure 3A. The absorption peaks of Si-O-Si at 1030, 778 and $442 \mathrm{~cm}^{-1}$ are derived from the network of the aerogels and the molecular chain of PHMS [27]. The peak at $1030 \mathrm{~cm}^{-1}$ is the asymmetric stretching vibration absorption peak of Si-O-Si, $778 \mathrm{~cm}^{-1}$ is attributable to the symmetric stretching vibration absorption peak of Si-O-Si and $442 \mathrm{~cm}^{-1}$ is attributable to the bending vibration absorption peak of Si-O-Si. The absorption peaks of $\mathrm{Si}-\mathrm{CH}_{3}$ are at 1270 and $840 \mathrm{~cm}^{-1}[28,29]$. The $\mathrm{Si}_{-} \mathrm{CH}_{3}$ comes from PHMS and the modifiers trimethylchlorosilane, methyltrimethoxysilane and methyltriethoxysilane introduced in the surface modification. At $960 \mathrm{~cm}^{-1}$, there is a symmetrical stretching vibration absorption peak of Si-O-C [30]. $\mathrm{Si}-\mathrm{O}-\mathrm{C}$ comes from the modifiers methyltrimethoxysilane and methyltriethoxysilane. The in-plane rocking absorption peak of $\mathrm{CH}_{2}$ is at $735 \mathrm{~cm}^{-1}$ [29], which comes from the $\mathrm{CH}_{2}-\mathrm{CH}_{2}$ group formed in the addition reaction. No absorption peak of the Si-H bond is observed at $2160 \mathrm{~cm}^{-1}$, which is due to the reaction between PHMS and formamide in isopropanol solvent, causing the $\mathrm{Si}-\mathrm{H}$ bond to be consumed. As shown in Figure 3B, with the increase in TEOS, the symmetric stretching vibration absorption peak of Si-O-Si at $778 \mathrm{~cm}^{-1}$ increases gradually, which indicates that there are more TEOSs undergoing condensation reaction with VTES. This reaction can improve the symmetry of Si-O-Si network and enhance the absorption peak.
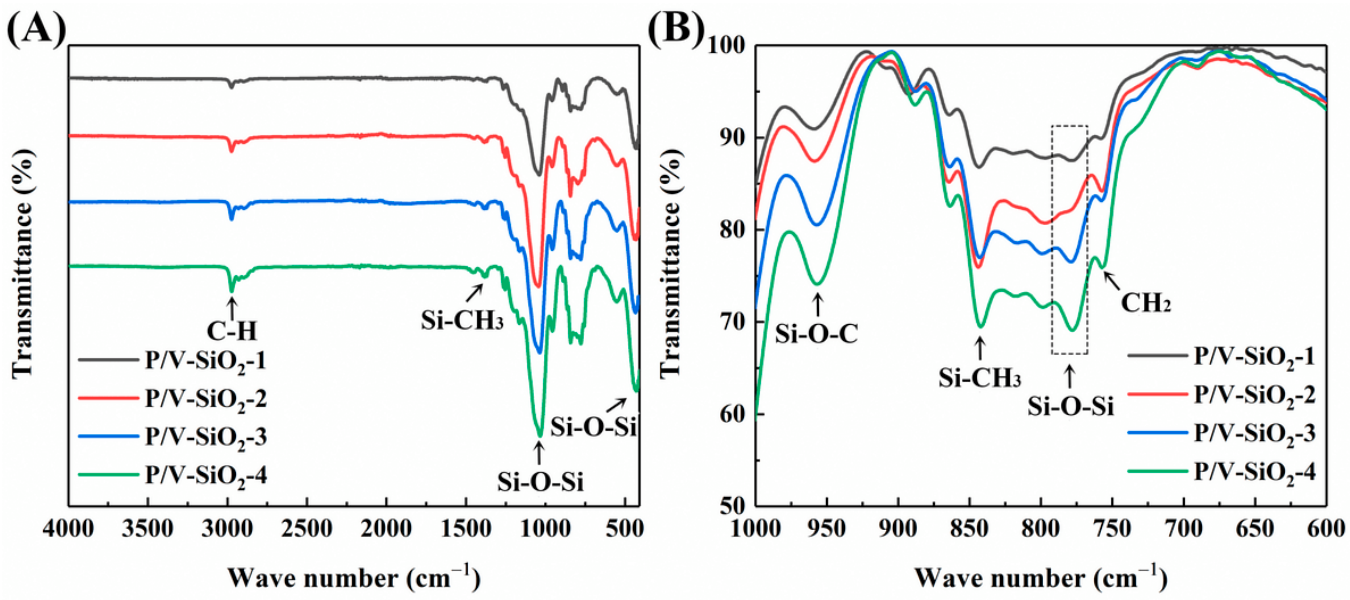

Figure 3. Infrared spectra of the composite aerogels: (A) samples $\mathrm{P} / \mathrm{V}-\mathrm{SiO}_{2}-1, \mathrm{P} / \mathrm{V}-\mathrm{SiO}_{2}-2, \mathrm{P} / \mathrm{V}-\mathrm{SiO}_{2}-3$ and $\mathrm{P} / \mathrm{V}-\mathrm{SiO}{ }_{2}-4$; (B) enlarged view of part of the spectra shown in (A), in the wavenumber range of $600-1000 \mathrm{~cm}^{-1}$.

\subsubsection{Microscopic Morphology}

The microscopic morphology of the composite aerogels is shown in Figure 4. With the decrease in PHMS and VTES, the aerogel particles gradually become smaller, and the 
particle size decreases from the range of $80-100 \mathrm{~nm}$ (the sample $\mathrm{P} / \mathrm{V}-\mathrm{SiO}_{2}-1$ is $85-100 \mathrm{~nm}$, and the sample $\mathrm{P} / \mathrm{V}-\mathrm{SiO}_{2}-2$ is $80-95 \mathrm{~nm}$ ) to $30-50 \mathrm{~nm}$ (the sample $\mathrm{P} / \mathrm{V}-\mathrm{SiO}_{2}-3$ and the sample $\mathrm{P} / \mathrm{V}-\mathrm{SiO}_{2}-4$ are both $30-50 \mathrm{~nm}$ ). This shows that, when the proportion of PHMS and VTES is high, the coating formed by PHMS and VTES wraps the inorganic aerogel particles, making the aerogel particles large. At this time, the agglomeration phenomenon of the aerogel particles becomes clear (Figure 4A). This is because the PHMS/VTES complex coated on aerogel particles continues to react with the adjacent aerogel particles, resulting in chemical bonding between aerogel particles. It causes the agglomeration of aerogel particles. Therefore, the proportion of PHMS and VTES determines the thickness of the coating, which affects the morphology and particle size of the composite aerogels.
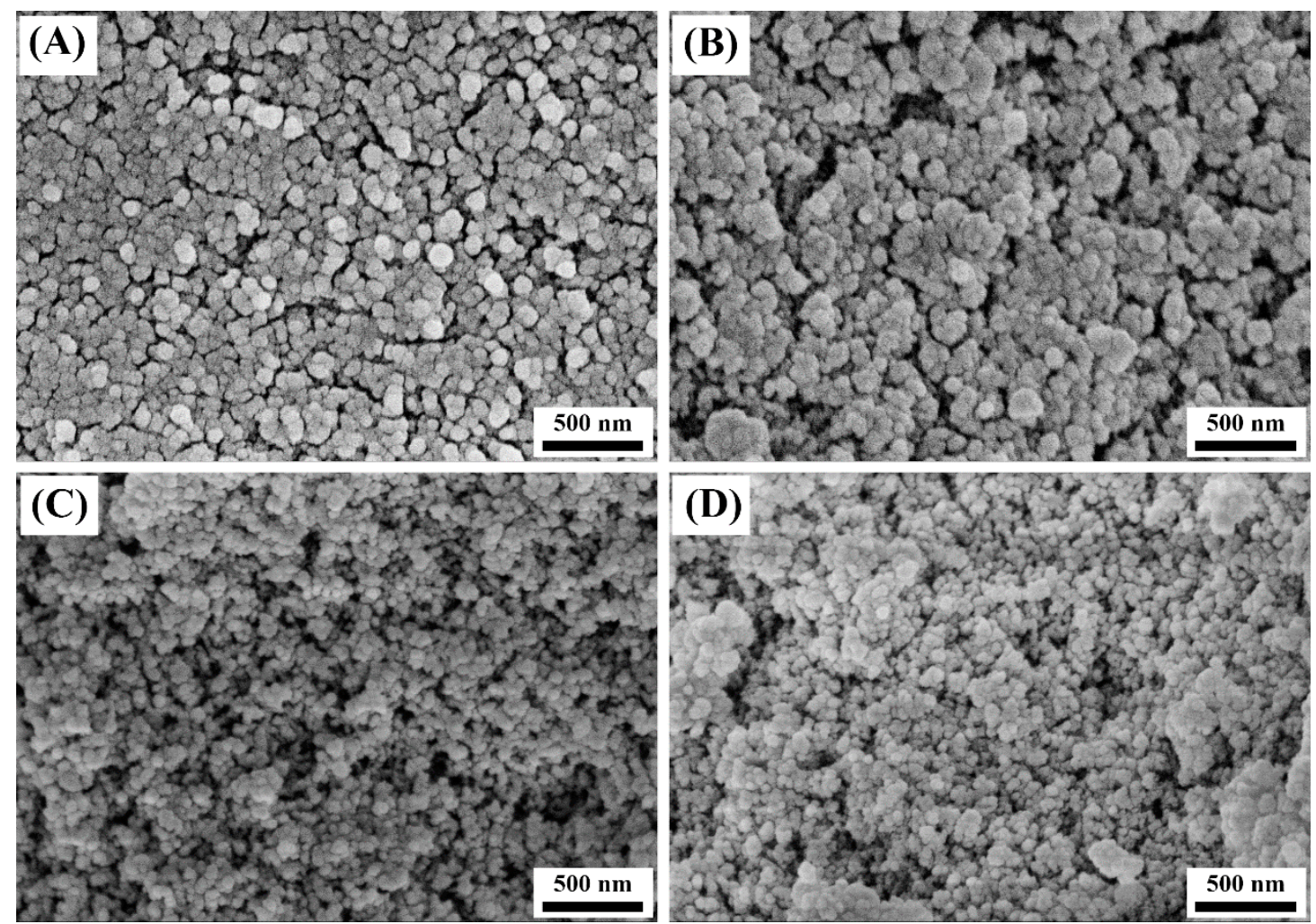

Figure 4. The microscopic morphology of the composite aerogels: (A) P/V-SiO $2-1$, (B) $\mathrm{P} / \mathrm{V}-\mathrm{SiO}_{2}-2,(\mathrm{C}) \mathrm{P} / \mathrm{V}-\mathrm{SiO}{ }_{2}-3$ and (D) $\mathrm{P} / \mathrm{V}-\mathrm{SiO}_{2}-4$.

\subsubsection{Pore Structure}

The $\mathrm{N}_{2}$ adsorption and desorption curves of the composite aerogels are shown in Figure 5A. The adsorption and desorption curves are all type IV curves according to the IUPAC classification [31,32], indicating that the composite aerogels are typical mesoporous materials. There is a hysteresis loop in the adsorption and desorption curves that is due to capillary condensation in the mesoporous materials [13]. The sample $\mathrm{P} / \mathrm{V}-\mathrm{SiO}_{2}-1$ shows a type $\mathrm{H} 2(\mathrm{~b})$ hysteresis loop, and the samples $\mathrm{P} / \mathrm{V}-\mathrm{SiO}_{2}-2, \mathrm{P} / \mathrm{V}-\mathrm{SiO}_{2}-3$ and $\mathrm{P} / \mathrm{V}-\mathrm{SiO}_{2}-4$ show a type $\mathrm{H} 1$ hysteresis loop [33]. These two types of hysteresis loops both show that the pore size distribution is uniform. The pore size distribution of the composite aerogels is shown in Figure 5B. The pore size is mainly in the range of $5-40 \mathrm{~nm}$, which is consistent with the characteristics of mesoporous materials [13]. With the increase in the PHMS/VTES complex, the pore size gradually decreases. 

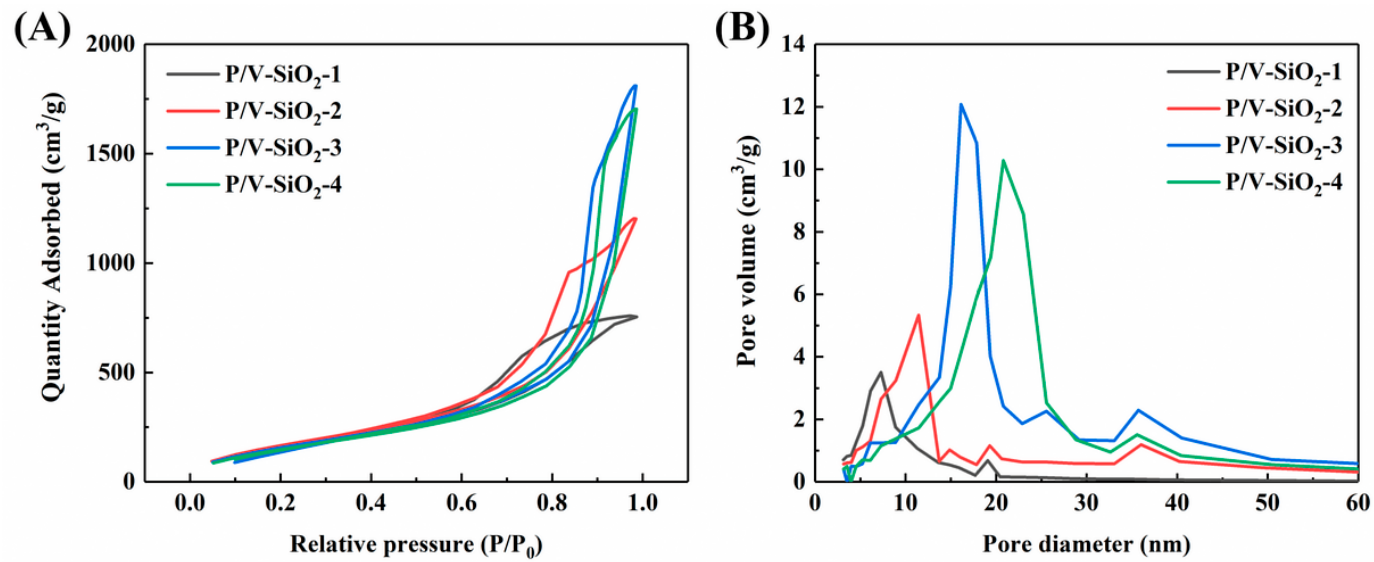

Figure 5. $\mathrm{N}_{2}$ adsorption and desorption analysis of the composite aerogels (samples $\mathrm{P} / \mathrm{V}-\mathrm{SiO}_{2}-1, \mathrm{P} / \mathrm{V}-\mathrm{SiO}_{2}-2, \mathrm{P} / \mathrm{V}-\mathrm{SiO}{ }_{2}-3$ and $\left.\mathrm{P} / \mathrm{V}-\mathrm{SiO}_{2}-4\right)$ : (A) adsorption and desorption curves and (B) pore size distribution.

The analysis results of the $\mathrm{N}_{2}$ adsorption and desorption of the composite aerogels are shown in Table 2. The most probable pore sizes of the composite aerogels are between 7 and $20 \mathrm{~nm}$. As the proportion of PHMS/VTES increases, the most probable pore size of the composite aerogels decreases. This is because the PHMS/VTES complex can bond with the inorganic Si-O-Si network. A coating structure forms on the aerogel particles, which makes the aerogel particles larger and the pore size smaller. This is consistent with the morphological characteristics shown in Figure 4. The analysis results show that the composite aerogels have high specific surface area. When the pore volume does not significantly change, the smaller the pore size, the larger the specific surface area. Therefore, when the proportion of PHMS/VTES increases, the pore size decreases and the specific surface area of the composite aerogels increases (sample $\mathrm{P} / \mathrm{V}-\mathrm{SiO}_{2}-2$ ). However, when the size of the aerogel particles further increases, the pore volume of aerogels decreases obviously, thus making the specific surface area of the composite aerogels decrease (sample $\left.\mathrm{P} / \mathrm{V}-\mathrm{SiO}_{2}-1\right)$.

Table 2. $\mathrm{N}_{2}$ adsorption and desorption analysis results of the composite aerogels.

\begin{tabular}{cccc}
\hline Samples & BET Specific Surface Area $\left(\mathbf{m}^{2} / \mathbf{g}\right)$ & Pore Volume $\left(\mathbf{c m}^{\mathbf{3}} / \mathbf{g}\right)$ & Pore Size $(\mathbf{n m})$ \\
\hline $\mathrm{P} / \mathrm{V}-S i O_{2}-1$ & 622.8 & 1.205 & 7.288 \\
$\mathrm{P} / \mathrm{V}^{-\mathrm{SiO}_{2}-2}$ & 673.1 & 1.922 & 11.43 \\
$\mathrm{P} / \mathrm{SiO}_{2}-3$ & 631.3 & 2.903 & 16.12 \\
$\mathrm{P} / \mathrm{V}^{-} \mathrm{SiO}_{2}-4$ & 599.7 & 2.691 & 20.82 \\
\hline
\end{tabular}

Compared with the typical inorganic $\mathrm{SiO}_{2}$ aerogels prepared with ethanol as the solvent, the composite aerogels we prepared have a larger pore size when the proportion of PHMS/VTES is low. This is related to changing in solvent from ethanol to isopropanol [34]. However, the use of isopropanol as a solvent is a necessary condition to achieve the mixing of the organic and inorganic components. It is difficult to achieve similar effects with ethanol.

\subsection{Properties of the Composite Aerogels}

\subsubsection{Thermal Properties}

The heat-transfer process of aerogels can be divided into two aspects: solid-phase heat transfer and gas-phase heat transfer. The solid-phase heat transfer depends on the aerogel framework, and the gas-phase heat transfer is closely related to the pore structure of aerogels. When the pore size of the aerogel is smaller than the mean free path of air molecules, the gas-phase heat transfer can be significantly reduced, and the thermal insulation properties of aerogels can be improved [35]. 
The thermal conductivity of the composite aerogels is shown in Figure 6. With the increase in PHMS and VTES, the thermal conductivity of the composite aerogels first decreases and then increases. The PHMS/VTES complex forms a coating on the aerogel particles. With the increase in PHMS and VTES, the thickness of the coating is increased (Figure 4). On the one hand, the thickening of the coating helps to improve the specific surface area of the composite aerogels (Table 2), reducing the gas-phase heat transfer and reducing the thermal conductivity of the composite aerogels. On the other hand, when the coating is too thick, the solid-phase heat transfer of the composite aerogels will increase and the thermal conductivity will also increase. Therefore, there is an optimal proportion of PHMS and VTES.

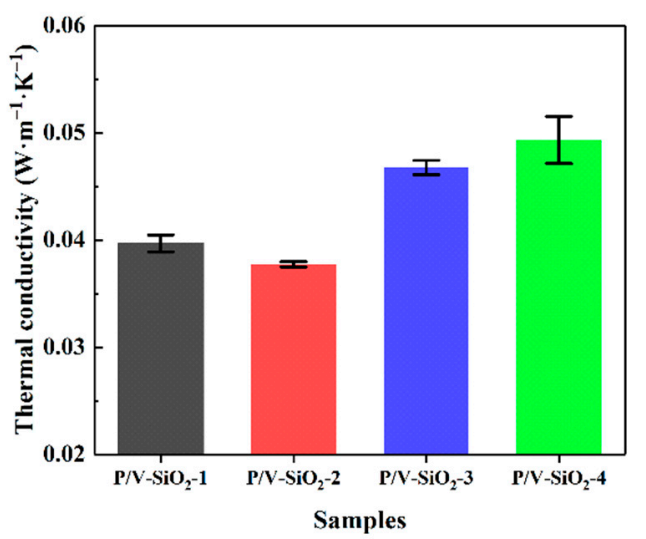

Figure 6. Thermal conductivity of the composite aerogels (samples $\mathrm{P} / \mathrm{V}-\mathrm{SiO}_{2}-1, \mathrm{P} / \mathrm{V}-\mathrm{SiO}_{2}-2$, $\mathrm{P} / \mathrm{V}-\mathrm{SiO}_{2}-3$ and $\left.\mathrm{P} / \mathrm{V}-\mathrm{SiO}_{2}-4\right)$.

As shown in Figure 6, when the raw-material ratio of the composite aerogels is PHMS:VTES:TEOS=1:0.3:5 (sample $\mathrm{P} / \mathrm{V}_{-} \mathrm{SiO}_{2}-2$ ), the best heat insulation properties are achieved. Thermal conductivity is as low as $0.03773 \mathrm{~W} \cdot \mathrm{m}^{-1} \cdot \mathrm{K}^{-1}$. Under the same conditions, we prepared inorganic $\mathrm{SiO}_{2}$ aerogels with only TEOS as the raw material, and its thermal conductivity is $0.03424 \mathrm{~W} \cdot \mathrm{m}^{-1} \cdot \mathrm{K}^{-1}$. Compared with the inorganic $\mathrm{SiO}_{2}$ aerogels, the thermal conductivity of the composite aerogels has not significantly increased [36]. It is shown that the method of simultaneously introducing long-chain molecules and small-molecule silane to prepare the composite aerogels does not significantly decrease the thermal insulation properties of aerogels.

\subsubsection{Mechanical Properties}

The stress-strain curves during compression and the compressive properties of the composite aerogels are shown in Figure 7. The compressive strength of the composite aerogels increases with the increase in the proportion of the organic components, PHMS and VTES. In our study, the compressive strength of the composite aerogels was 1.87-2.28 $\mathrm{MPa}$ (samples $\mathrm{P} / \mathrm{V}-\mathrm{SiO}_{2}-1, \mathrm{P} / \mathrm{V}-\mathrm{SiO}_{2}-2$ ), while the compressive strength of the inorganic $\mathrm{SiO}_{2}$ aerogels was usually less than $0.6 \mathrm{MPa}[10,11]$. At the same time, we have tested the inorganic $\mathrm{SiO}_{2}$ aerogels prepared with isopropanol as a solvent under the same conditions, and the compressive strength was also only $0.740 \mathrm{MPa}$. Therefore, the mechanical properties of the composite aerogels with the PHMS/VTES complex are significantly better than those of the inorganic $\mathrm{SiO}_{2}$ aerogels. 

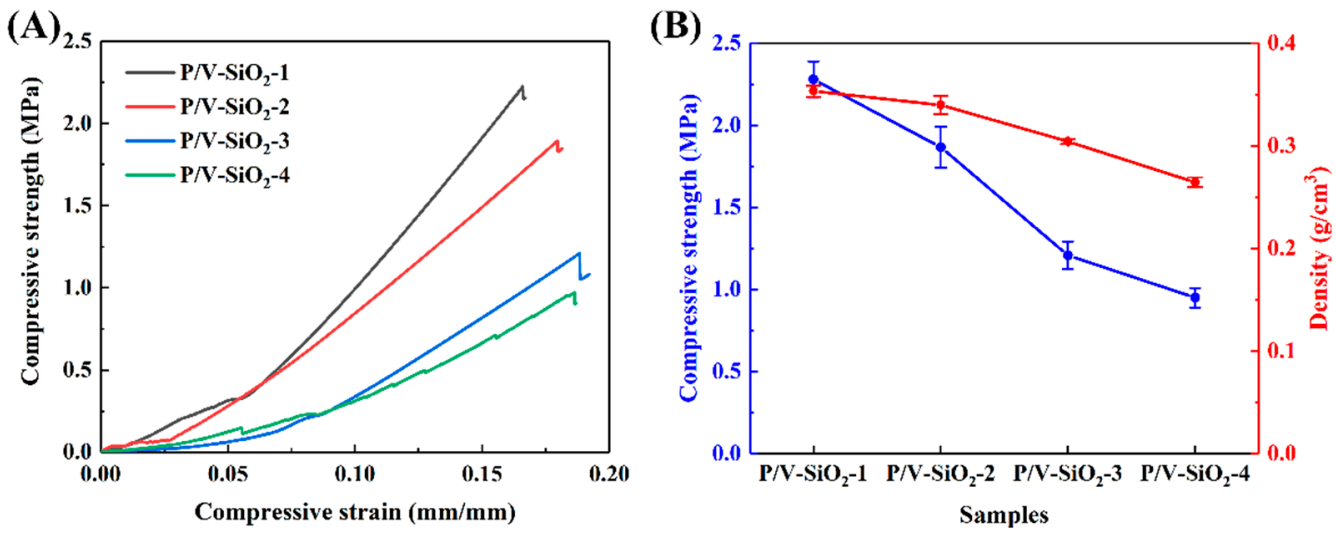

Figure 7. Compressive performance of the composite aerogels (samples $\mathrm{P} / \mathrm{V}-\mathrm{SiO}_{2}-1, \mathrm{P} / \mathrm{V}-\mathrm{SiO}_{2}-2, \mathrm{P} / \mathrm{V}-\mathrm{SiO}_{2}-3$ and $\left.\mathrm{P} / \mathrm{V}_{-} \mathrm{SiO}_{2}-4\right)$ : (A) stress-strain curves and $(\mathbf{B})$ compressive strength and density.

According to Figure 7A, when the proportion of PHMS/VTES is small (samples $\left.\mathrm{P} / \mathrm{V}-\mathrm{SiO}_{2}-3, \mathrm{P} / \mathrm{V}-\mathrm{SiO}_{2}-4\right)$, the stress-strain curves of the composite aerogels show the characteristics of typical brittle materials [37]. When the proportion of PHMS/VTES is high (samples $\mathrm{P} / \mathrm{V}-\mathrm{SiO}_{2}-1$ and $\mathrm{P} / \mathrm{V}-\mathrm{SiO}_{2}-2$ ), the composite aerogels have a large compression shape in the initial stage of the load application. At this stage, the PHMS/VTES coating is the main reason for the deformation. Figure $7 \mathrm{~B}$ also shows the density of the composite aerogels. With the increase in PHMS and VTES, the density of the composite aerogels gradually increases. This is because the PHMS/VTES complex is coated on the inorganic aerogel particles, resulting in a higher density. The density of the composite aerogels has a positive correlation with mechanical properties, and both of them increase with the increase of PHMS/VTES. Moreover, the PHMS/VTES complex is not only the factor that increases the density of the aerogels but also the factor that enhances the mechanical properties of the aerogels.

\section{Discussion}

We use linear polymer (PHMS) and low-molecular-weight silane (VTES) to form a coating structure on the aerogel particles. The coating affects the structure of the composite aerogels. It is the reason that the composite aerogels have high specific surface area, excellent thermal insulation properties and mechanical properties. In order to obtain this coating structure, we improved the one-pot synthesis method. Firstly, the liquid PHMS/VTES complex was prepared by the addition reaction between PHMS and VTES. Next, the liquid PHMS/VTES complex was mixed with the inorganic silica sol, and the composite aerogels were prepared by the one-pot synthesis method. In this way, the carbon-carbon double bond of VTES avoids being destroyed by strong acid added during the hydrolysis of silica sol, which can ensure the formation of the PHMS/VTES complex.

Figure $8 \mathrm{~A}-\mathrm{C}$ shows the effect of different proportions of PHMS/VTES on the morphology of the aerogel particles. Firstly, the PHMS/VTES complex forms a coating on the aerogel particles that makes the aerogel particles larger. The organic components have a higher density. With an increase in the particle size, the density of the composite aerogels increase. Secondly, when the proportion of PHMS/VTES is higher, the PHMS/VTES complex accumulated between the aerogel particles is increased, as shown in Figure 8A, which results in the agglomeration of the aerogel particles. The SEM images in Figure 4 prove this. At the same time, the PHMS/VTES complex does not change the porous structure of the aerogels. The composite aerogels can maintain a high specific surface area of more than $600 \mathrm{~m}^{2} / \mathrm{g}$ (Table 2). Therefore, the preparation method we proposed can maintain the advantages of the high specific surface area of the aerogels. 
(A)

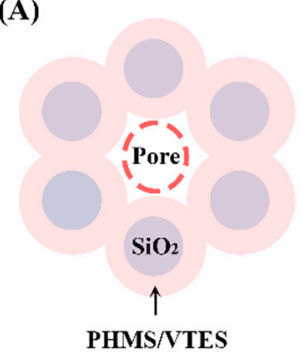

(B)

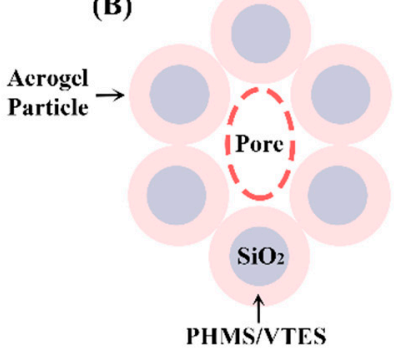

(C)

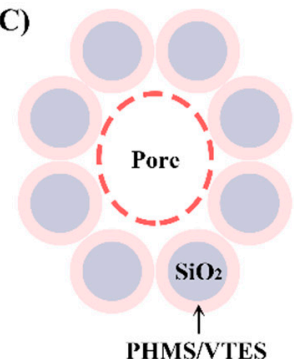

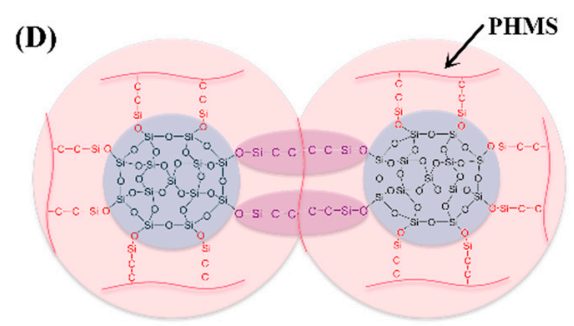

Figure 8. The schematic diagram of the composite aerogel particles with different proportion of PHMS/VTES: (A) sample P/V-SiO $2-1$, (B) sample P/V-SiO $2-2$ and (C) sample $\mathrm{P} / \mathrm{V}-\mathrm{SiO}_{2}-3$. (D) The connection method of the adjacent aerogel particles.

Figure 8A-C shows the two modes of heat conduction of the aerogels: solid-phase heat transfer by the aerogel particles, and gas-phase heat transfer by pores. When the proportion of PHMS/VTES is too high (Figure 8A), the PHMS/VTES coating is too thick, and the particle size and density increase, resulting in an increase in solid-phase heat transfer [38]. When the proportion of PHMS/VTES is too small (Figure 8C), the aerogels have a larger pore size, which makes porosity increase and density decrease, resulting in an increase in gas-phase heat conduction [39]. Both of these conditions cause the thermal conductivity of the aerogels to increase. Therefore, there is an optimal proportion of PHMS/VTES, at which the negative impact of PHMS/VTES on the thermal insulation properties of the composite aerogels is minimized (Figure 6). This is the reason that sample $\mathrm{P} / \mathrm{V}-\mathrm{SiO}_{2}-2$ exhibits the best thermal insulation properties.

Figure $8 \mathrm{D}$ shows the chemical bond between the composite aerogel particles. Due to the PHMS/VTES complex, chemical bonds can form between the aerogel particles. Therefore, the adjacent aerogel particles are connected by the PHMS/VTES complex. As the proportion of PHMS/VTES increases, the agglomeration of the aerogel particles becomes clear (Figure 4). The connection strength of the secondary particles is improved [40], which enhances the compressive strength of the composite aerogels (Figure 7).

Considering the thermal insulation properties (Figure 6) and the mechanical properties (Figure 7), the sample $\mathrm{P} / \mathrm{V}-\mathrm{SiO}_{2}-2$ has the best thermal insulation properties and better mechanical properties, achieving a balance between thermal insulation properties and mechanical properties. It proves that the composite aerogels we prepared can achieve an improvement in comprehensive properties.

\section{Conclusions}

In this study, we prepared the PHMS/VTES-SiO 2 composite aerogels with low thermal conductivity and high compressive strength. It is proved that the PHMS/VTES complex can be compounded with $\mathrm{SiO}_{2}$ aerogel particles by wrapping. Through this compound method, the mechanical properties of aerogels can be improved. At the same time, the network structure of aerogels is maintained, and the thermal insulation properties is not significantly reduced. We discuss the effect of the PHMS/VTES complex on the network structure of the composite aerogels, thermal insulation properties and mechanical properties. When the composite aerogel ratio of PHMS:VTES:TEOS is 1:0.3:5, the best thermal insulation properties and better mechanical properties are obtained. At this ratio, 
the thermal conductivity is $0.03773 \mathrm{~W} \cdot \mathrm{m}^{-1} \cdot \mathrm{K}^{-1}$ and the compressive strength is $1.87 \mathrm{MPa}$, which achieves a balance between thermal insulation and mechanical properties. This study expands the research platform for composite aerogels and proposes a combination approach in which long-chain molecules and low-molecular-weight silanes are introduced. This concept should provide a basis for improving the mechanical properties and network stability of silica aerogels.

Author Contributions: Conceptualization, D.S. and H.J.; methodology, D.S.; software, W.W.; validation, W.W. and R.L.; formal analysis, W.W. and Z.T; investigation, W.W.; resources, D.S. and H.J.; data curation, W.W.; writing—original draft preparation, W.W.; writing—review and editing, Z.T., D.S. and H.J.; visualization, W.W.; supervision, D.S. and H.J.; project administration, D.S. and H.J.; funding acquisition, D.S. and H.J. All authors have read and agreed to the published version of the manuscript.

Funding: This research was funded by National Natural Science Foundation of China (grant number 51972222) and Natural Science Foundation of Tianjin City (No. 19JCYBJC18200).

Institutional Review Board Statement: Not applicable.

Informed Consent Statement: Not applicable.

Data Availability Statement: Data are contained within the article.

Conflicts of Interest: The authors declare no conflict of interest. The funders had no role in the design of the study; in the collection, analyses or interpretation of data; in the writing of the manuscript; or in the decision to publish the results.

\section{References}

1. Smith, D.M.; Maskara, A.; Boes, U. Aerogel-based thermal insulation. J. Non-Cryst. Solids 1998, 225, 254-259. [CrossRef]

2. Fricke, J.; Emmerling, A. Aerogels—recent progress in production techniques and novel applications. J. Sol-Gel Sci. Technol. 1998, 13, 299-303. [CrossRef]

3. Rao, A.P.; Rao, A.V. Modifying the surface energy and hydrophobicity of the low-density silica aerogels through the use of combinations of surface-modification agents. J. Mater. Sci. 2010, 45, 51-63.

4. Nguyen, B.N.; Meador, M.A.B.; Tousley, M.E.; Shonkwiler, B.; Mccorkle, L.; Scheiman, D.A. Tailoring elastic properties of silica aerogels cross-linked with polystyrene. ACS Appl. Mater. Interfaces 2009, 1, 621-630. [CrossRef]

5. Meyer, E.; Milow, B.; Ratke, L. Development of aerogel additives for the foundry industry. J. Supercrit. Fluids 2015, 106, 62-68. [CrossRef]

6. Zhang, Y.; Shen, Q.; Li, X.; Xie, H.; Nie, C. Facile synthesis of ternary flexible silica aerogels with coarsened skeleton for oil-water separation. RSC Adv. 2020, 10, 42297-42304. [CrossRef]

7. Boday, D.J.; Keng, P.Y.; Muriithi, B.; Pyun, J.; Loy, D.A. Mechanically reinforced silica aerogel nanocomposites via surface initiated atom transfer radical polymerizations. J. Mater. Chem. 2010, 20, 6863-6865. [CrossRef]

8. $\mathrm{Si}$, Y.; Yu, J.; Tang, X.; Ge, J.; Ding, B. Ultralight nanofibre-assembled cellular aerogels with superelasticity and multifunctionality. Nat. Commun. 2014, 5, 5802. [CrossRef] [PubMed]

9. Domínguez, M.; Taboada, E.; Idriss, H.; Molins, E.; Llorca, J. Fast and efficient hydrogen generation catalyzed by cobalt talc nanolayers dispersed in silica aerogel. J. Mater. Chem. 2010, 20, 4875-4883. [CrossRef]

10. Lei, Y.; Hu, Z.; Cao, B.; Chen, X.; Song, H. Enhancements of thermal insulation and mechanical property of silica aerogel monoliths by mixing graphene oxide. Mater. Chem. Phys. 2017, 187, 183-190. [CrossRef]

11. Yue, S.; Li, X.; Yu, H.; Tong, Z.; Liu, Z. Preparation of high-strength silica aerogels by two-step surface modification via ambient pressure drying. J. Porous Mater. 2021, 1-9. [CrossRef]

12. Jiang, L.; Kato, K.; Mayumi, K.; Yokoyama, H.; Ito, K. One-pot synthesis and characterization of polyrotaxane-silica hybrid aerogel. ACS Macro Lett. 2017, 6, 281-286. [CrossRef]

13. He, S.; Chen, X. Flexible silica aerogel based on methyltrimethoxysilane with improved mechanical property. J. Non-Cryst. Solids 2017, 463, 6-11. [CrossRef]

14. Kanamori, K.; Aizawa, M.; Nakanishi, K.; Hanada, T. Elastic organic-inorganic hybrid aerogels and xerogels. J. Sol-Gel Sci. Technol. 2008, 48, 172-181. [CrossRef]

15. Duan, Y.; Jana, S.C.; Lama, B.; Espe, M.P. Reinforcement of silica aerogels using silane-end-capped polyurethanes. Langmuir 2013, 29, 6156-6165. [CrossRef]

16. Li, X.; Wang, Q.; Li, H.; Ji, H.; Sun, X.; He, J. Effect of sepiolite fiber on the structure and properties of the sepiolite/silica aerogel composite. J. Sol-Gel Sci. Technol. 2013, 67, 646-653. [CrossRef] 
17. Hayase, G.; Kanamori, K.; Abe, K.; Yano, H.; Maeno, A.; Kaji, H.; Nakanishi, K. Polymethylsilsesquioxane-cellulose nanofiber biocomposite aerogels with high thermal insulation, bendability, and superhydrophobicity. ACS Appl. Mater. Interfaces 2014, 6, 9466-9471. [CrossRef] [PubMed]

18. Li, S.; Ren, H.; Zhu, J.; Bi, Y.; Xu, Y.; Zhang, L. Facile fabrication of superhydrophobic, mechanically strong multifunctional silica-based aerogels at benign temperature. J. Non-Cryst. Solids 2017, 473, 59-63. [CrossRef]

19. Zu, G.; Kanamori, K.; Shimizu, T.; Zhu, Y.; Maeno, A.; Kaji, H.; Nakanishi, K.; Shen, J. Versatile double-cross-linking approach to transparent, machinable, supercompressible, highly bendable aerogel thermal superinsulators. Chem. Mater. 2018, 30, 2759-2770. [CrossRef]

20. Hegde, N.D.; Rao, A.V. Physical properties of methyltrimethoxysilane based elastic silica aerogels prepared by the two-stage sol-gel process. J. Mater. Sci. 2007, 42, 6965-6971. [CrossRef]

21. Yang, Z.; Yu, H.; Li, X.; Ding, H.; Ji, H. Hyperelastic and hydrophobic silica aerogels with enhanced compressive strength by using VTES/MTMS as precursors. J. Non-Cryst. Solids 2019, 525, 119677. [CrossRef]

22. Hayase, G.; Kanamori, K.; Hasegawa, G.; Maeno, A.; Kaji, H.; Nakanishi, K. A superamphiphobic macroporous silicone monolith with marshmallow-like flexibility. Angew. Chem. 2013, 125, 10988-10991. [CrossRef]

23. Ma, J.; Ye, F.; Lin, S.; Zhang, B.; Yang, H.; Ding, J.; Yang, C.; Liu, Q. Large size and low density SiOC aerogel monolith prepared from triethoxyvinylsilane/tetraethoxysilane. Ceram. Int. 2017, 43, 5774-5780. [CrossRef]

24. Liu, H.L.; Chu, P.; Li, H.Y.; Li, J.; Han, Y.K. Preparation and properties of silica aerogels reinforced using polyurethanes via ambient pressure drying. J. Synth. Cryst. 2015, 44, 3532-3536.

25. Lin, J.; Chen, H.; Fei, T.; Liu, C.; Zhang, J. Highly transparent and thermally stable superhydrophobic coatings from the deposition of silica aerogels. Appl. Surf. Sci. 2013, 273, 776-786. [CrossRef]

26. Coates, J. Interpretation of Infrared Spectra, a Practical Approach. In Encyclopedia of Analytical Chemistry: Applications, Theory and Instrumentation; John Wiley and Sons: Hoboken, NJ, USA, 2016.

27. Yang, J.; Chen, J.; Song, J. Studies of the surface wettability and hydrothermal stability of methyl-modified silica films by FT-IR and Raman spectra. Vib. Spectrosc. 2009, 50, 178-184. [CrossRef]

28. Sarawade, P.B.; Kim, J.K.; Kim, H.K.; Kim, H.T. High specific surface area TEOS-based aerogels with large pore volume prepared at an ambient pressure. Appl. Surf. Sci. 2007, 254, 574-579. [CrossRef]

29. Al-Oweini, R.; El-Rassy, H. Synthesis and characterization by FTIR spectroscopy of silica aerogels prepared using several Si (OR) 4 and $\mathrm{R}^{\prime \prime} \mathrm{Si}\left(\mathrm{OR}^{\prime}\right) 3$ precursors. J. Mol. Struct. 2009, 919, 140-145. [CrossRef]

30. Pan, K.; Zeng, X.; Li, H.; Lai, X. Synthesis of silane oligomers containing vinyl and epoxy group for improving the adhesion of addition-cure silicone encapsulant. J. Adhes. Sci. Technol. 2016, 30, 1131-1142. [CrossRef]

31. Ghosh, M.; Lohrasbi, M.; Chuang, S.S.; Jana, S.C. Mesoporous titanium dioxide nanofibers with a significantly enhanced photocatalytic activity. ChemCatChem 2016, 8, 2525-2535. [CrossRef]

32. Radi, S.; El Abiad, C.; Moura, N.M.; Faustino, M.A.; Neves, M.G.P. New hybrid adsorbent based on porphyrin functionalized silica for heavy metals removal: Synthesis, characterization, isotherms, kinetics and thermodynamics studies. J. Hazard. Mater. 2019, 370, 80-90. [CrossRef]

33. Taheri, P.; Lang, J.C.; Kenvin, J.; Kroll, P. Differential hysteresis scanning of non-templated monomodal amorphous aerogels. Phys. Chem. Chem. Phys. 2021, 23, 5422-5430. [CrossRef]

34. Hilonga, A.; Kim, J.K.; Sarawade, P.B.; Kim, H.T. Low-density TEOS-based silica aerogels prepared at ambient pressure using isopropanol as the preparative solvent. J. Alloys Compd. 2009, 487, 744-750. [CrossRef]

35. Koebel, M.; Rigacci, A.; Achard, P. Aerogel-based thermal superinsulation: An overview. J. Sol-Gel Sci. Technol. 2012, 63, 315-339. [CrossRef]

36. Wei, T.Y.; Chang, T.F.; Lu, S.Y.; Chang, Y.C. Preparation of monolithic silica aerogel of low thermal conductivity by ambient pressure drying. J. Am. Ceram. Soc. 2007, 90, 2003-2007. [CrossRef]

37. Ma, J.; Ye, F.; Yang, C.; Ding, J.; Lin, S.; Zhang, B.; Liu, Q. Heat-resistant, strong alumina-modified silica aerogel fabricated by impregnating silicon oxycarbide aerogel with boehmite sol. Mater. Des. 2017, 131, 226-231. [CrossRef]

38. Hrubesh, L.W.; Pekala, R.W. Thermal properties of organic and inorganic aerogels. J. Mater. Res. 1994, 9, 731-738. [CrossRef]

39. Zeng, S.Q.; Hunt, A.; Greif, R. Transport properties of gas in silica aerogel. J. Non-Cryst. Solids 1995, 186, 264-270. [CrossRef]

40. Maleki, H.; Durães, L.; Portugal, A. An overview on silica aerogels synthesis and different mechanical reinforcing strategies. J. Non-Cryst. Solids 2014, 385, 55-74. [CrossRef] 